Proceedings of SALT 21: 532-551, 2011

\title{
Instrumental with and use: modality and implicature
}

\author{
Lilia Rissman \\ Johns Hopkins University
}

\begin{abstract}
I present an analysis of the instrumental elements with and use, as in Betty cut the cake with a knife. A variety of evidence indicates that with and use do not make the same semantic contribution, casting doubt on the theory that these elements introduce the thematic role Instrument. For use, I adopt the analysis in Rissman (to appear): use expresses modal, goal-related content. For with, a modal reading may be implicated but is not entailed, explaining a variety of contrasts between with and use. The implications of this analysis for a theory of thematic roles is discussed.
\end{abstract}

Keywords: thematic roles, instruments, implicature, event representation

\section{Introduction}

The underlined elements in (1) are commonly referred to as "instruments:"

(1) a. Cinderella scrubbed the floor with an old toothbrush.

b. Cinderella used an old toothbrush to scrub the floor.

At first glance, the sentences in (1) appear to be truth-conditionally equivalent. Indeed, the supposed synonymy of such sentences has motivated the claim that with and use both introduce the abstract case/thematic role Instrument (Fillmore 1968, Lakoff 1968, Nilsen 1973, Koenig, Mauner, Bienvenue \& Conklin 2008). The elements with and use are not in fact subject to the same constraints, however:

(2) a. While he was sleeping, Jim mopped the floor with his sleeping bag. ${ }^{1}$ b. *While he was sleeping, Jim used his sleeping bag to mop the floor.

\footnotetext{
* This work was supported by an NSF IGERT grant to the JHU Cognitive Science department. Thank you to Kyle Rawlins, Paul Smolensky and members of the JHU Semantics Lab for invaluable feedback and advice. Thank you also to the attendees of SALT 21, NELS 41 and MACSIM 2010 for their questions and discussion.

${ }^{1}$ Thanks to an anonymous SALT reviewer.
} 
Instrumental with and use

(3) a. I used my heritage to grow and become a better person.

b. *I grew and became a better person with my heritage.

My analysis of with and use improves on previous analyses of instruments in three ways: the analysis avoids unanalyzed predicates such as MEANS or BY (Rappaport \& Levin 1988, Jackendoff 1990), allows for instruments that are not causal intermediaries and accounts for with/use contrasts. This paper focuses on the contrast in (2) but I also sketch an account of the contrast in (3). For use, I adopt the analysis in Rissman (to appear): use expresses modal, goal-related content. Specifically, worlds where the instrument is part of the event are more consistent with the agent's goals than some world where the instrument is not involved. With sentences may also have modal readings, but this reading is only implicated, not entailed. I argue that the contrasts in (2-3) cast doubt on the view that thematic roles such as Instrument have a primitive status in the grammar. In this paper, the term "instrument" is a theory-neutral reference to the object of with or use.

In Section 2, I review previous analyses of instrumental meaning. In Section 3, I summarize the analysis of use presented in Rissman (to appear): use involves a comparison between worlds where the instrument is and is not involved; these worlds are ranked with respect to the agent's goals. I argue in Section 4 that with implicates but does not entail this beneficial modal reading, and discuss how this implicature arises. In Section 5, I consider an explanation for the contrast in (3). I conclude in Section 6 with a discussion of the relevance of this work to theories of thematic roles.

\section{Previous work on instruments}

The view that with and use both introduce the thematic role Instrument is a familiar one. In his monograph on Instrumental case, Nilsen (1973: 17-19) writes: "in 1968, George Lakoff... concluded that with and use share so many cooccurrence constraints that they are actually derived from the same underlying base... as a result of his paper, many case grammarians decided that a noun

phrase was to be considered Instrumental if and only if it could be the object of both with and use and still carry the same meaning." More recently, Koenig et al. (2008) express a similar view: "the object of with and the direct object of use target very similar, if not identical, L-thematic roles" (180).

From this perspective, a possible response to the contrasts in (2-3) is that the underlined elements are simply not Instruments, as they cannot appear as the object of both with and use. Lakoff (1968), for example, observes that whereas with has both accidental and intentional senses, use has only an intentional sense. He states that only the intentional sense of with is relevant to the case role 
Instrument. Rather than assume the existence of the role Instrument and set aside with/use differences, a more informative approach, in my view, is to investigate with and use as separate elements, providing a compositional analysis that captures both their similarities and differences.

Whether or not Instrument is assumed to be a grammatical primitive, precisely characterizing the role of the instrument in an event is a major challenge. Some analyses rely on undefined predicates and so lack explanatory force: in Rappaport \& Levin 1988, for example, (1a) denotes an event where Cinderella scrubs the floor BY MEANS OF her bringing the toothbrush into contact with the floor. In Jackendoff 1990, the predicate BY serves a similar function. Another approach is to analyze an instrument as a causal intermediary (Talmy 1976, Croft 1991, Goldberg 2002, Koenig et al. 2008). For example, Croft (1991) describes the instrument as "intermediate in a causal chain between the subject (initiator) and the direct object (final affected entity)" (178). Such a description captures the role of the instrument in sentences such as (4):

(4) Margie sliced the bread with a knife.

The knife is a causal intermediary in the sense that Margie causes the knife to come into contact with the bread, which causes the bread to become sliced.

As Schlesinger (1995) and Koenig et al. (2008) point out, however, instruments may play different types of roles in events:

(5) a. Jim ate ice cream with a spoon.

b. Chloe used a ladder to paint the ceiling.

Jim acting on the spoon does not CAUSE him to eat the ice cream; likewise Chloe acting on the ladder does not CAUSE her to paint the ceiling. In these sentences, the spoon and ladder play only "facilitating" or "helping" roles (Marantz 1984, Koenig et al. 2008, respectively).

As I point out in Rissman (to appear), instrumental role is not entirely determined by verbal meaning; a single verb may allow multiple instrument roles:

(6) a. Chloe used a serrated knife to cut the bread.

b. Chloe amazingly used her foot to cut the bread. (implicit knife)

c. Chloe used a ladder to cut the highest branches from the tree.

An analysis of use and with must be flexible enough to account for the variety of instrumental roles shown in (4-6), while avoiding unanalyzed terms such as MEANS and BY. 
Instrumental with and use

\section{Analysis of use: summary of Rissman (to appear)}

In Rissman (to appear), I argue that use sentences entail that the instrument plays a beneficial role in the event. The ladder in (5b), for example, is facilitative in the sense that Chloe can paint the ceiling more quickly or easily by climbing the ladder, or perhaps Chloe would be simply unable to reach the ceiling without the ladder. In other words, use has a modal reading: it involves a comparison between worlds where the instrument is part of the event and worlds where it is not. Crucially, I argue that these worlds are ranked with respect to the goals of the agent. For example, (5b) conveys that for all worlds where Chloe paints the ceiling and acts on the ladder, there exists some lower-ranked world where Chloe paints the ceiling but does not act on the ladder. This lower-ranked world might conflict with Chloe's goals of doing tasks quickly, not getting paint on herself, etc.

The presence of a goal-based ordering source allows for the variety of instrumental roles demonstrated in (4-6): the instrument need not play any particular role in the causal event sequence, but must simply fulfill some subset of the goals of the agent. The goal-based analysis of use also accounts for the sharp infelicity of (2b): use is not possible in an unintentional context because only intentional agents have goals. Additionally, this analysis establishes a connection between use-sentences and structurally similar rationale clauses, which have received a goal-based analysis in the literature on anankastic conditionals (Sæbø 2001, von Fintel \& Iatridou 2004/2005, von Stechow, Krasikova \& Penka 2005, Huitink 2005, Nissenbaum 2005, Werner 2006): ${ }^{2}$

(7) Jane took the A-train in order to go to Harlem.

Formally, the analysis in Rissman (to appear) utilizes a type-driven, Montague-style compositional semantics and the lambda calculus notation developed in Heim \& Kratzer 1998. Use is type $\langle\mathrm{e}\langle\langle\mathrm{vt}\rangle\langle\mathrm{vt}\rangle\rangle\rangle$, where $\mathrm{v}$ is the type of events. Use has two arguments: the instrumental DP (type e) and the infinitival clause (type $\langle v t\rangle)$. Following Kratzer (1996), Voice introduces the subject:

\footnotetext{
${ }^{2}$ Anankastic conditionals and rationale clauses have similar meanings:

i. If you want to go to Harlem, you have to take the A-train.

ii. You have to take the A- train in order to go to Harlem.
} 


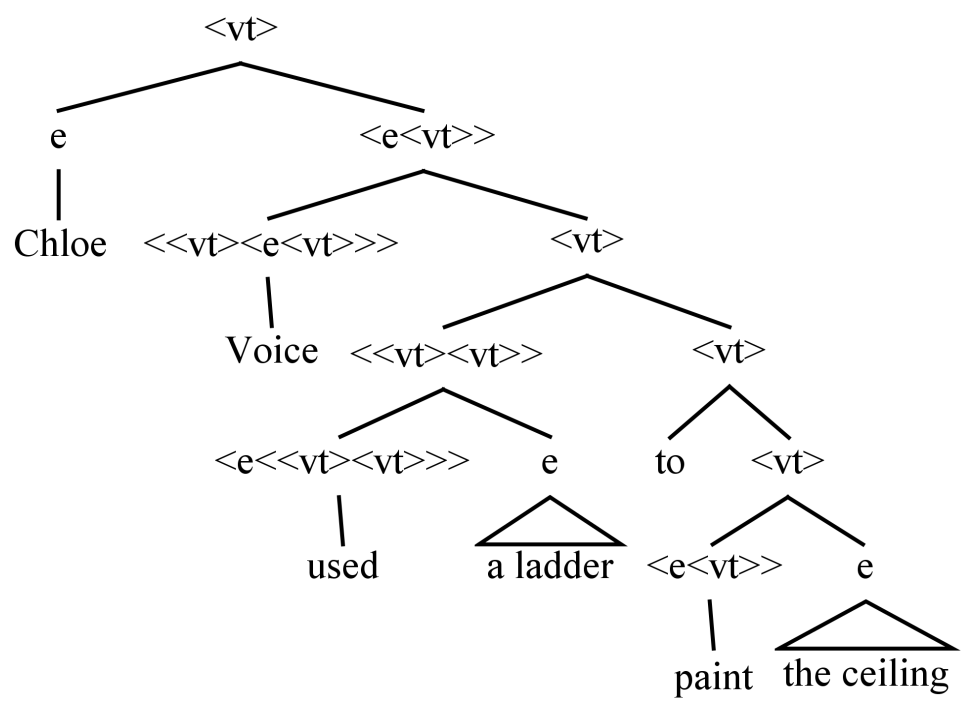

Figure 1 Compositional parse tree for Chloe used a ladder to paint the ceiling.

Use entails the existence of an event $e$ such that $e^{\prime}$ is a subevent of $e$. The instrument is the patient of the subevent $e^{\prime}$, indicating that the agent "acts on" the instrument. The particular property $\mathrm{P}(\mathrm{e})$ is contributed by the infinitival clause. For all worlds where both $e$ and $e^{\prime}$ occur, there exists some world less highly ranked with respect to the agent's goals where $e$ occurs but $e$ does not occur:

$$
\begin{aligned}
& \llbracket u s e \rrbracket^{\mathrm{c}, \mathrm{w}}=\lambda \mathrm{x} \in \mathrm{D}_{\mathrm{e} \cdot} \cdot \lambda \mathrm{P}_{<\mathrm{vt}>} \cdot \lambda \mathrm{e}^{\prime} \in \mathrm{D}_{\mathrm{v}} \cdot \operatorname{Pat}\left(\mathrm{e}^{\prime}, \mathrm{x}\right) \wedge \\
& \exists \mathrm{e}: \mathrm{e}^{\prime} \subset_{\mathrm{w}} \mathrm{e} \wedge \mathrm{P}(\mathrm{e}) \wedge \operatorname{Ag}\left(\mathrm{e}^{\prime}\right)=\operatorname{Ag}(\mathrm{e}) \wedge \mathrm{O}(\mathrm{e})(\mathrm{w}) \wedge \mathrm{O}\left(\mathrm{e}^{\prime}\right)(\mathrm{w}) \wedge \\
& \forall \mathrm{w}^{\prime}:\left(\mathrm{w}^{\prime} \in \cap \mathrm{f}(\mathrm{w}) \wedge \mathrm{O}(\mathrm{e})\left(\mathrm{w}^{\prime}\right) \wedge \mathrm{O}\left(\mathrm{e}^{\prime}\right)\left(\mathrm{w}^{\prime}\right)\right) \rightarrow \\
& \left(\exists \mathrm{w}^{\prime \prime}:\left(\mathrm{w}^{\prime \prime} \in \cap \mathrm{f}(\mathrm{w}) \wedge \mathrm{O}(\mathrm{e})\left(\mathrm{w}^{\prime \prime}\right) \wedge \neg \mathrm{O}\left(\mathrm{e}^{\prime}\right)\left(\mathrm{w}^{\prime \prime}\right) \wedge \mathrm{w}^{\prime}<\mathrm{g}(\mathrm{w}) \mathrm{w}^{\prime \prime}\right)\right)
\end{aligned}
$$

$\mathrm{O}(\mathrm{e})(\mathrm{w}) \equiv$ e occurs in $\mathrm{w}$; $\mathrm{e}^{\prime} \subset_{\mathrm{w}} \mathrm{e} \equiv \mathrm{e}^{\prime}$ is a subevent of $\mathrm{e}$ in $\mathrm{w} ; \mathrm{f}(\mathrm{w})$ is a circumstantial modal base; $\mathrm{g}(\mathrm{w})$ is an agent-oriented teleological ordering source. Strict partial order defined as in von Fintel \& Iatridou 2004/2005:

(9) For any set of propositions $\mathrm{P},<_{\mathrm{P}}$ is defined as:

$$
\forall \mathrm{w}^{\prime}, \mathrm{w}^{\prime \prime}: \mathrm{w}^{\prime}<_{\mathrm{P}} \mathrm{w}^{\prime \prime} \text { iff } \forall \mathrm{p} \in \mathrm{P}\left(\mathrm{w}^{\prime \prime} \in \mathrm{p} \rightarrow \mathrm{w}^{\prime} \in \mathrm{p}\right) \wedge \exists \mathrm{p} \in \mathrm{P}\left(\mathrm{w}^{\prime} \in \mathrm{p} \wedge \mathrm{w}^{\prime \prime} \notin \mathrm{p}\right)
$$

Applying the denotation in (8) to (5b), $e$ is a painting event and $e^{\prime}$ might be an event of Chloe climbing the ladder. The circumstantial modal base $\mathrm{f}(\mathrm{w})$ contains 
Instrumental with and use

relevant facts about $\mathrm{w}$, such as that Chloe is 6 feet tall, her ceiling is 9 feet tall, and her ladder is 8 feet tall. The ordering source $\mathrm{g}(\mathrm{w})$ contains propositions expressing Chloe's goals in w, such as wanting to do tasks quickly and not get paint on her clothes. Use expresses that for all worlds in which Chloe paints the ceiling and acts on the ladder, there exists a lower-ranked world in which Chloe paints the ceiling but does not act on the ladder. For example, $w^{\prime \prime}$ could be a world where Chloe jumps up and down in order to reach the ceiling with a brush.

\section{Analysis of with}

\subsection{Contrasts between with and use}

As discussed in Section 2, previous researchers have observed that not all instruments play a causal intermediary role. The role of the with-instruments in (10) has been characterized as enabling (Nilsen 1973), facilitating (Marantz 1984), or helping (Koenig et al. 2008):

(10) a. Larry walks with a cane.

b. Carla lifted the logs with a pulley.

c. Jim ate the ice cream with a spoon.

The intuition behind these labels is clear: we interpret (10a) as conveying not just that the cane was involved in the walking event, but that the cane somehow made the walking easier for Larry. Similarly for $(10 \mathrm{~b})$, we have the reading that the pulley made the job of lifting easier or more efficient for Carla.

Koenig et al. (2008) provide a definition of what it means to "help," paraphrased in (11): ${ }^{3}$

(11) $e_{1}$ helps e2 iff $e_{1}$ causes $e_{2}$ to be higher on a pragmatically defined scale than it would otherwise have been

This definition of helping and my analysis of use share the notion that instrumentality involves a comparison of situations, with +instrument situations being better than some set of -instrument situations. In this sense, the sentences in (10) have a "beneficial" reading. This reading may be captured by a goal-based analysis: worlds where Larry acts on the cane are more consistent with his goal of walking without pain and exhaustion; worlds where Jim acts on the spoon are more consistent with his goal of not getting his hands sticky, etc.

\footnotetext{
${ }^{3}$ In contrast with my analysis of $u$ se, which is verb-general, help appears in the denotation of particular verbs such as eat, play and hunt.
} 
With-sentences do not entail goal-based modality, however. Unlike useinstruments, with-instruments are permitted in non-intentional contexts; (2a) is repeated here as $(12 \mathrm{a})$ :

(12) a. While he was sleeping, Jim mopped the floor with his sleeping bag.

b. Nancy accidentally cut her dress with the scissors.

c. The bus crushed the tricycle with its tire.

d. Jim tripped and broke the vase with his elbow.

None of the use variants of these sentences is felicitous.

Additionally, the beneficial reading for with sentences does not necessarily arise when the instrument fills a verbal argument role:

(13) a. Jim cut the bread with a knife.

b. Martha hit the fence with a stick.

c. Suzanne poked the man with her finger.

Following Koenig et al. (2008), I assume that verbs such as cut, hit and poke encode an argument role that may be filled by an instrument. Cut, for example, encodes a relation between three participants: Participant A causes Participant B to come into contact with Participant $\mathrm{C}$ such that $\mathrm{B}$ makes an incision in C. (13ac) indicate that the instrument plays a particular role as specified by the verb, but not that situations where the instrument is involved are necessarily better in any way. Note the contrast between the with-sentences in (13) and their use counterparts:

(14) a. Jim used a knife to cut the bread.

b. Martha used a stick to hit the fence.

c. Suzanne used her finger to poke the man.

In (14a), although the instrument fills a verbal argument role, we still have the reading that Jim is making an intentional choice in using the knife, i.e. that acting on the knife satisfies some subset of his goals. This reading is missing from the with sentences in (13).

On the basis of the data in (12-14), I argue that the beneficial reading present in (10) is only implicated, rather than entailed. Unlike use, with does not entail a 


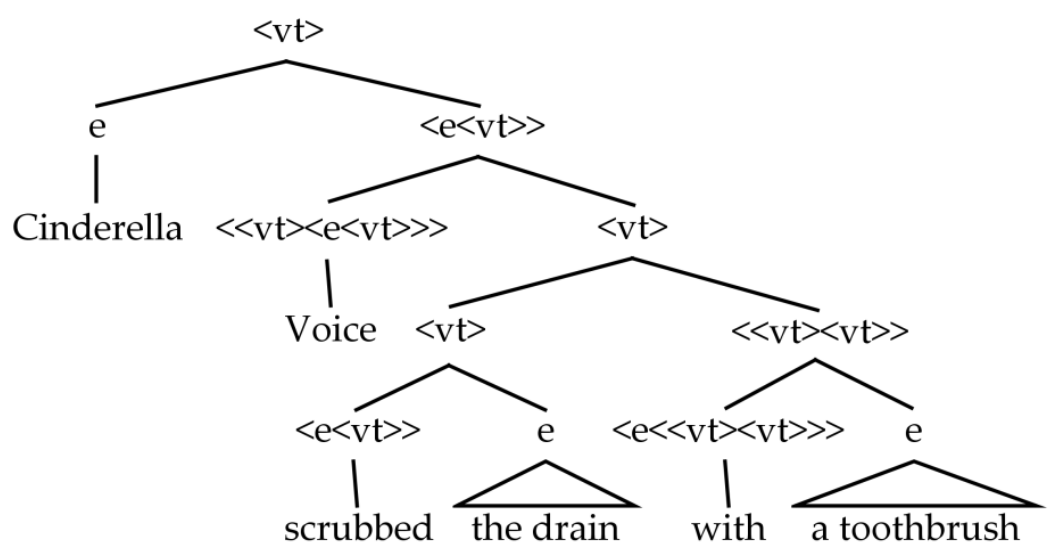

Figure 2 Compositional parse tree for Cinderella scrubbed the drain with a toothbrush.

ranking over worlds; instead, the denotation of with includes only the extensional portion of the meaning of $u s e:^{4}$

$$
\begin{aligned}
& \llbracket \text { with } \rrbracket^{\mathrm{c}, \mathrm{w}}=\lambda \mathrm{x} \in \mathrm{D}_{\mathrm{e} .} \lambda \mathrm{P}_{<\mathrm{vt}>} \cdot \lambda \mathrm{e} \in \mathrm{D}_{\mathrm{v} .} \\
& \mathrm{P}(\mathrm{e}) \wedge \exists \mathrm{e}^{\prime}: \mathrm{e}^{\prime} \subset_{\mathrm{w}} \mathrm{e} \wedge \operatorname{Pat}\left(\mathrm{e}^{\prime}, \mathrm{x}\right) \wedge \operatorname{Ag}\left(\mathrm{e}^{\prime}\right)=\operatorname{Ag}(\mathrm{e})
\end{aligned}
$$

The argument structure of with and its relationship to the rest of the clause is shown in Figure 2.

Applying the denotation in (15) to (10c), $e$ is an eating event and there exists a subevent $e^{\prime}$ in which Jim "acts on" the spoon. The reading that the spoon helped Jim eat the ice cream arises via conversational implicature. In Section 4.2 I consider how this implicature arises, and in Section 4.3 I present additional evidence that with has the relatively underspecified meaning shown in (15).

\subsection{Instrumental implicatures}

\section{Neo-Gricean calculation}

The beneficial reading for (10c), repeated here as (16a), arises via Gricean inference. Instead of saying (16a), the speaker could have said (16b):

\footnotetext{
${ }^{4}$ With presupposes the existence of the instrumental subevent e'. For use, e' is an argument; see Rissman (to appear) for details.
} 
(16) a. Jim ate the ice cream with a spoon.

b. Jim ate the ice cream.

Because the with-phrase is a syntactically optional adjunct, saying (16a) is a potential violation of the Maxim of Quantity-2: "do not make your contribution more than is required in the context of the exchange" (wording from Matsumoto 1995). The hearer assumes that the speaker is observing the Quantity-2 Maxim, and so infers that mentioning the spoon is required in the exchange. More specifically, the hearer infers that the spoon was somehow significant in the eating event. The hearer may then make a number of different inferences about how the spoon was significant: the spoon may have made it easier to eat the ice cream, or might have been physically salient in the event, or perhaps eating the ice cream would not have been possible without the spoon. In cases where a goalbased reading is possible, the implicature possibly has the modal content expressed in the third and fourth lines of the denotation of use in (8).

In cases such as (13), where the instrument fills a verbal argument role, the with-phrase is also a syntactically optional adjunct. As such, the hearer still makes an inference about why the speaker did not utter the less informative alternative, based on observance of Quantity-2. In this case, however, a prominent inference is that the significance of the instrument to the event is that it fills a verbally-specified role. The prominence of this inference leads the sentences in (13) to lack a salient beneficial reading. Such sentences are not prohibited from having beneficial readings, however:

(17) Tammy sliced off the branch with a chainsaw.

Here, the reading that the chainsaw "helped" Tammy is more salient, potentially because slicing a branch off a tree is more physically effortful than cutting bread, and so the role of the chainsaw is more important. Such variation in the strength of the beneficial reading is expected under an analysis where listeners make an inference about how the instrument might be significant in an event.

\section{Inhibitory Instruments}

If observance of Quantity-2 leads to the implicature that the instrument is significant, with a variety of options for inferring how the instrument is significant, this predicts that with-sentences should not necessarily have beneficial readings. That is, it should be possible for the instrument to play an inhibitory role. Such a reading is clearly not available for the sentences in (10). In other contexts, however, the instrument may in fact be interpreted as inhibitory: 
Instrumental with and use

(18) a. Jane attempted to clean her clothes with the muddy water from the river. b. Jim was a master portrait artist, but he struggled to paint her picture with watercolors.

The most salient reading of (18a) is that acting on the muddy water actually prohibited Jane from cleaning her clothes. Likewise in (18b), the inference is that having to use watercolors impeded Jim's ability to paint a life-like portrait. This inhibitory reading is not possible for use sentences; note the stark contrast between (19a-b):

(19) a. Jim struggled to cut the bread with scissors.

b. ?? Jim struggled to use scissors to cut the bread.

These sentences are clearly not synonymous. To the extent that (19b) is interpretable at all, it seems to mean something like Jim struggled to decide to use scissors to cut the bread. For use the instrument can only play a beneficial role, as predicted by the goal-based analysis.

Why then is an inhibitory reading not possible for the sentences in (10)? One possibility is that by default, we interpret events as proceeding in a steady, uninterrupted fashion. That is, when we read (10c), our default assumption is that the eating event was not impeded by Jim slipping on the kitchen floor, or cutting his finger on the edge of the spoon. Thus the spoon is interpreted as being part of an uninterrupted eating event, ruling out the inference that the spoon plays an inhibitory role. To override the default interpretation, a sentence must contain an explicit marker that the progression of the event was impeded; attempted to and struggled to serve this role in (18-19).

This explanation draws on an intuition familiar from analyses of the English progressive, as in (20):

(20) Mary was climbing Mt. Toby.

The analyses in Dowty 1977/1979, Landman 1992 and Portner 1998, for example, invoke our knowledge about uninterrupted events. Roughly speaking, these analyses hold that (20) is true if Mary succeeds in climbing Mt. Toby, given an uninterrupted climbing event. In Portner 1998, for example, the progressive is a modal operator; its modal base includes circumstances relevant to the event, such as that Mary is in good physical condition and does not give up easily. The ordering source includes propositions about how the event might be uninterrupted, e.g. "Mary does not get eaten by a bear," "Mary does not twist her ankle," etc. Under this analysis, (20) is true if the best circumstantially accessible worlds are 
worlds where Mary climbs Mt. Toby. Although the sentences in (10) do not involve a modal operator, I suggest that the propositions in the ordering source of the progressive, e.g. "Jim does not cut his finger on the edge of the spoon," are still part of the contextual knowledge surrounding an event.

\section{With implicature may be blocked}

Although with-sentences often convey that the instrument plays a beneficial role, I have argued that this reading is an implicature. If this analysis is correct, we would expect that this implicature should not arise in all contexts. One such context is illustrated in (21) (Barbara Partee, p.c.):

(21) A: Look at this fancy glass spoon. Is it supposed to be ornamental or what? B: Well, Jim just ate some ICE CREAM with the spoon, so I guess it's not ornamental.

We interpret B's utterance to mean that the spoon was involved in the eating event, but not that its role was particularly significant. The relevance of the spoon to the discourse requires that $\mathrm{B}$ mention it, blocking the listener from considering the less informative alternative John just ate some ice cream. If this alternative is not considered, there is no possible Quantity-2 violation and no inference about the significance of the spoon in the event arises. The sense that the spoon must have played a facilitative rather than an inhibitory role is again due to our default assumption that events proceed in an uninterrupted fashion.

\subsection{Additional evidence for underspecified with meaning}

If the beneficial reading for with-sentences is generated via implicature, we would expect to find independent evidence that with has the underspecified meaning in (15). By the same token, evidence for an underspecified with predicts that the beneficial reading has pragmatic origins. One such piece of evidence involves the "locatum" sense of with shown in (22): ${ }^{5}$

(22) a. Jim loaded the truck with hay.

b. Betty covered the table with a cloth.

c. Joan filled the vase with water.

(22a-c) also fail to entail a beneficial reading, suggesting that locatum with has the same denotation as "instrumental" with.

\footnotetext{
${ }^{5}$ Clark \& Clark (1979) introduce the term "locatum" as a description of this sense.
} 
The preposition with has many senses other than the instrumental sense, including comitative (I danced with my partner) and manner (I sewed the blanket with care). Locatum with has most often been discussed in the literature on the English locative alternation (Rappaport \& Levin 1988, Pinker 1989, Goldberg 2002, Iwata 2005/2008). ${ }^{6}$ By definition, locatum with appears following a verb of "putting" (Levin 1993) such as load or cover, and names the substance that is being transferred to a location such as a truck or a table. Unlike the comitative and manner senses of with, the locatum sense is not easily distinguished from the instrumental sense. Goldberg (2002), for example, analyzes both types of withphrases as instances of the INTERMEDIARY construction. Likewise, Koenig et al. (2008) classify both participant types as Instruments, given that locatum phrases may also be introduced by use:

(23) a. Jim used hay to load the truck.

b. Betty used a cloth to cover the table.

c. Joan used water to fill the vase.

As with the cut/hit/poke sentences in (13), (22a-c) do not have a prominent beneficial reading. That is, $(22 \mathrm{c})$ conveys simply that Joan transferred the water into the vase such that the vase became full, without the sense that the water helped Joan accomplish this task. Not all analyses of with equate the locatum and instrumental senses (Levin \& Rappaport 1988, McKercher 2001, Iwata 2008). ${ }^{7}$ In my view, however, the primary motivation for distinguishing these senses is that locatum sentences do not readily give rise to beneficial readings. Given the evidence that instrumental with sentences also do not entail beneficial readings, the most parsimonious explanation is that instrumental and locatum with are one and the same.

\footnotetext{
${ }^{6}$ Some but not all verbs can "alternate" between with and into/onto variants:

i. Jim loaded the truck with hay.

ii. Jim loaded hay onto the truck.

iii. Joan filled the glass with water.

iv. *Joan filled water into the glass.

${ }^{7}$ Some researchers have argued that instrumental and locatum with phrases differ with respect to syntactic argument diagnostics (Levin \& Rappaport 1988, Randall 1992, see Iwata 2008 for

discussion). For example, Levin \& Rappaport report the contrast between (i) and (ii):

i. Bill loaded the truck with a crane and Don did so with a forklift.

ii. *Bill loaded the truck with cartons and Don did so with trunks.

This judgment is not universally agreed upon (see Goldberg 2002). In a grammaticality judgment task, Rissman (2010) found that non-linguist subjects did not distinguish (i) from (ii).
} 
Under this analysis, the ambiguity of (24) arises via two different implicature calculations, not because of two different lexical entries for with:

Jim filled the tank with a hose.

The most natural reading of (24) is that the hose transported water or some other liquid into the tank. A second possibility, however, is that the hose itself comes to be located inside the tank. These readings arise from different inferences about the significant role of the hose in the filling event: the hose may play a helping role, or may fill a verbal argument role.

Cross-linguistic patterns of instrument/locatum expression provide additional evidence that these two participant types are closely linked. I queried speakers of Spanish, Turkish, Tamil, Korean and Japanese and found that in each of these languages, instruments and locata are introduced with the same marker, as in English:

(25) Spanish

a. Llen-é el tanque con una manguera.

Fill-1SG.PST DEF.M tank with INDEF.F hose

"I filled the tank with a hose."

b. Llen-é el tanque con agua.

Fill-1SG.PST DEF.M tank with water.

"I filled the tank with water."

(26) Turkish

a. Ben kek-i biçak-la kesti-u. 1SG cake-ACC knife- INSTR cut-PST

"I cut the cake with a knife."

b. Ben bardag-i su -yla doldur-du.

1SG glass-ACC water-INSTR fill-PST

"I filled the glass with water."

(27) Tamil

a. Naan bread-aj katti-aal naru-kk-inen.

1SG bread-ACC knife-INSTR cut-PST-1SG

"I cut the bread with a knife."

b. Naan bread-aj towel-aal muDi-n-en.

1SG bread-ACC towel-INSTR cover-PST-1SG

"I covered the bread with a towel." 
Instrumental with and use

(28) Korean

a. Na-nun pan- eul kal -ro jal-lat-ta. 1SG-TOP bread-ACC knife -INSTR cut-PST-DEC

"I cut the bread with a knife."

b. Na-nun cup- eul mul ro chae-wot-da.

1SG-TOP cup-ACC water -INSTR fill/load-PST-DEC

"I filled the glass with water."

(29) Japanese

a. Watashi-wa pan-o naifu-de kitta.

1SG -TOP bread-ACC knife-with cut

"I cut the bread with a knife."

b. Watashi-wa koppu-o mizu-de mitashita.

1SG -TOP glass-ACC water-with filled

"I filled the glass with water."

With this informal sampling of languages, I do not intend to suggest that this pattern will be cross-linguistically universal, nor that each of the bolded markers in (25-29) has the same meaning as English with. Nonetheless, if instrumental and locatum with were entirely distinct lexical items, we would not expect that other languages would consistently use the same morphological marker to introduce these participant types. If instrumental and locatum with convey the same meaning, however, the uniformity in (25-29) is less surprising.

\subsection{Summary of with analysis}

In Section 4 I discussed several contrasts between with and use: with-sentences do not require an intentional agent and do not necessarily convey a beneficial reading when the instrument fills a verbal argument role, for example. To account for these and other factors, I proposed that the denotation of with includes only extensional content; the common beneficial reading is implicated rather than entailed. This implicature arises through observance of the Maxim of Quantity-2, predicting that with-instruments should not necessarily play a beneficial role. I provided examples of such inhibitory instruments, and suggested why inhibitory readings do not arise by default. An extensional analysis of with allows instrumental and locatum with to share the same meaning, consistent with previous analyses and cross-linguistic data.

\section{Additional contrasts between with and use}

In this section I consider the contrasts in (30-31); (3) is repeated here as (30): 
(30) a. I used my heritage to grow and become a better person.

b. *I grew and became a better person with my heritage.

(31) a. Nixon used the Secret Service to investigate the Senate majority leader.

b. ?? Nixon investigated the Senate majority leader with the Secret Service.

Although Chomsky (1972) notes the similar contrast in (32), this contrast between with and use is relatively under-explored:

(32) a. John used his connections to further his career.

b. *John furthered his career with his connections.

Analyses of the Instrumental role sometimes invoke the concept of "control" (Nilsen 1973, Schlesinger 1995). In Van Valin \& Wilkins (1996), for example, instruments are "inanimate entities which are not capable of independent motion or action and are subject to the control of another effector" (317). Indeed, the instruments in (30-32) are all in a sense outside the control or manipulation of the agent. The Secret Service and a set of connections are complex organizations of animate humans; one's heritage is an amalgam of past events and cultural ideas. Note that with allows non-concrete instruments, so long as the agent has some degree of control over the instrument:

(33) a. I analyzed my data with SPSS.

b. I found information about Linux with the New York Times search tool.

c. She outsmarted me with her cunning intellect.

With-sentences are particularly bad when both the agent and the instrument are human individuals:

(34) a. Jim used his supermodel girlfriend to get into clubs.

b. *Jim got into clubs with his supermodel girlfriend.

One explanation for these data is that with-instruments must be controlled by the agent, whereas use-instruments are not constrained with respect to this feature.

Animate instruments do not appear to be absolutely prohibited, however. If the agent has a sufficiently high degree of dominance over the animate instrument, a with-sentence is acceptable:

(35) a. The US killed Osama bin Laden with the Navy SEALs.

b. The US investigated Noriega with the Secret Service. 
Instrumental with and use

These sentences are even better when its replaces the in the with-PP, possibly reinforcing the dominance relation between the agent and the instrument:

(36) a. The US killed Osama bin Laden with its Navy SEALs.

b. The US investigated Noriega with its Secret Service.

Strictly speaking, the U.S. does not directly control the actions of individual members of the Secret Service. The existence of this group of individuals is within the organizational hierarchy of the U.S. government however, so in this sense the Secret Service is dominated by the U.S. The crucial question is whether the notion of control should be expanded to include this notion of dominance, or whether these are two separate constraints. I leave future research to consider how these constraints might be more precisely characterized.

In the denotation for with that I propose, the requirement that the instrument be controlled is encoded in the predicate $\operatorname{Pat}\left(\mathrm{e}^{\prime}, \mathrm{x}\right)$. Rather than representing a single atomic predicate, I conceive of $\operatorname{Pat}\left(\mathrm{e}^{\prime}, \mathrm{x}\right)$ and $\operatorname{Ag}(\mathrm{e})$ as referring to clusters of proto-role properties, as in Dowty 1991. In with and use, these predicates refer to different clusters of properties: for example, in the denotation of use, $\operatorname{Ag}(\mathrm{e})$ encodes the requirement that the agent be intentional. In the denotation of with, however, $\operatorname{Ag}(\mathrm{e})$ does not encode this property. For with but not use, $\operatorname{Pat}\left(\mathrm{e}^{\prime}, \mathrm{x}\right)$ encodes the constraint that the instrument be controlled.

\section{Discussion and conclusions}

A common view of thematic roles is that they encode a coherent semantic generalization. For example, Gruber (1965) characterizes a Theme as an entity "which is conceived as moving" (48). If we adopt the view described in Nilsen 1973, that "a noun phrase [is] to be considered Instrumental if and only if it [can] be the object of both with and use and still carry the same meaning," then it should be the case that these contexts form a semantically coherent class. Summarizing the data presented in this paper, I observe that these contexts, contexts where with and use may be semantically interchanged, have the following properties: the agent acts intentionally, the instrument does not fill a verbal argument role, there is no explicit indication that the progress of the event is impeded, and the agent has direct control over the instrument. This list of properties is clearly not semantically coherent. Additionally, what thematic role label should be assigned in cases where with and use are not interchangeable? For example, in John accidentally broke the vase with his elbow, what is the role of John's elbow if not an Instrument? 
I argue that the notion Instrument has limited functional value in explaining the data presented in this paper. Rather, assessing the semantic properties of with and use separately offers more explanatory coverage. This approach raises the question of why with and use-sentences should ever appear to be truthconditionally equivalent. That is, does treating with and use as entirely distinct fail to capture some generalization? One possibility is that the notion of Instrument reflects a conceptual prototype of a tool: a small object manipulated by an intentional agent with the goal of achieving some result or action. Neither with nor use encode this prototype. Rather, a set of concepts underlies the tool prototype, including ideas about goals, intention, causation, and control, and with and use encode these concepts in different ways. For with, some of these tool concepts are expressed via implicature, whereas others are encoded in the denotation itself.

This perspective borrows heavily from Dowty's 1991 theory of thematic proto-roles. In this theory, the grammar does not encode linking rules such as Agent $\rightarrow$ Subject. Rather, verbs entail proto-agent and patient properties of their arguments, such as causation, volition, undergoing change of state and being an incremental theme. The argument with the most agentive properties maps to subject, and the argument with the most patient properties maps to object. ${ }^{8}$ An appealing aspect of Dowty's theory is that cognitively-central concepts such as causation, sentience and intention play a crucial explanatory role. Such concepts have received considerable attention in research on non-linguistic cognition. For example, Carey (2011) argues that reasoning about the intentions and goals of animate, sentient beings is a system of core cognition, having a long evolutionary history and being developmentally innate. Carey also argues that representations of cause are conceptually innate, including representations of causal motion and state change events. Given the body of research investigating concepts of causation and intention in adults, children and non-human animals (see Saxe \& Carey 2006, Woodward 2009), I do not adopt the view that these concepts are no more explanatory than traditional thematic roles such as Agent, Patient and Theme (see Van Valin \& Wilkins 1996, for example). ${ }^{9}$

Many aspects of this work remain for further investigation. An analysis of instrumental with and use should ultimately include an account of the subevent relation between $e$ and $e^{\prime}$, addressing how this relation is constrained. Additionally, the grammatical mechanism whereby the predicates $\operatorname{Ag}(\mathrm{e})$ and Pat $\left(\mathrm{e}^{\prime}, \mathrm{x}\right)$ are linked to sets of proto-role properties should be elaborated. Finally, future work may explore the range of possible with implications, including formal statements of their semantic content.

\footnotetext{
${ }^{8}$ Note that my analysis of instruments is different from what Dowty himself proposes: he states that Instruments involve causation and movement without volition or sentience.

${ }^{9}$ Dowty attributes a similar view to Chierchia (Dowty 1991: 575).
} 
Instrumental with and use

\section{References}

Carey, Susan. 2009. The Origin of Concepts. New York, NY: Oxford University Press.

Chomsky, Noam. 1972. Studies on Semantics in Generative Grammar. The Hague: Mouton.

Clark, Eve V. \& Herbert H. Clark. 1979. When nouns surface as verbs. Language 55(4), 767-811.

Croft, William. 1991. Syntactic Categories and Grammatical Relations: the Cognitive Organization of Information. Chicago: University of Chicago Press.

Dowty, David. 1979. Word Meaning and Montague Grammar. Dordrecht: D. Reidel.

Dowty, David R. 1977. Toward a semantic analysis of verb aspect and the English 'imperfective' progressive. Linguistics and Philosophy 1(1), 45-77.

Fillmore, Charles J. 1968. The case for case. In Emmon W. Bach \& Robert T. Harms (eds.), Universals in Linguistic Theory, 210. New York: Holt, Rinehart and Winston.

von Fintel, Kai \& Sabine Iatridou. 2004/2005. What to do if you want to go to Harlem: notes on anankastic conditionals and other related matters. Ms., drafts at: [http:web.mit.edu/fintel/www/harlem.pdf]/ [http://mit.edu/fintel/ www/harlem-austin.pdf].

Goldberg, Adele E. 2002. Surface generalizations: an alternative to alternations. Cognitive Linguistics 13(4), 327-56.

Gruber, Jeffrey. 1965. Studies in Lexical Relations. Massachusetts Institute of Technology. Dept. of Modern Languages dissertation.

Heim, Irene \& Angelika Kratzer. 1998. Semantics in Generative Grammar. Malden, MA: Blackwell.

Huitink, Janneke. 2005. Anankastic conditionals and salient goals. Proceedings of Sinn and Bedeutung 9, 140-154.

Iwata, Seizi. 2005. Locative alternation and two levels of verb meaning. Cognitive Linguistics 16(2), 355-407.

Iwata, Seizi. 2008. Locative alternation: a Lexical Constructional Approach. Amsterdam: John Benjamins.

Jackendoff, Ray. 1990. Semantic Structures. Cambridge, MA: MIT Press.

Koenig, Jean-Pierre, Gail Mauner, Breton Bienvenue \& Kathy Conklin. 2008. What with? The anatomy of a (proto)-role. Journal of Semantics 25(2), 175220.

Kratzer, Angelika. 1996. Severing the external argument from its verb. In Johan Rooryck \& Laurie Zaring (eds.), Phrase Structure and the Lexicon, 109-137. Dordrecht, Netherlands: Kluwer Academic Publishers. 
Lakoff, George. 1968. Instrumental adverbs and the concept of deep structure. Foundations of Language 4(1), 4-29.

Landman, Fred. 1992. The Progressive. Natural Language Semantics 1, 1-32.

Levin, Beth \& Malka Rappaport. 1988. Nonevent -er nominals. Linguistics 26(6), 1067-83.

Marantz, Alec. 1984. On the Nature of Grammatical Relations. Cambridge, MA: MIT Press.

Matsumoto, Yo. 1995. The Conversational condition on horn scales. Linguistics and Philosophy 18(1), pp. 21-60.

McKercher, David A. 2002. The Polysemy of "with" in First Language Acquisition. Stanford University Department of Linguistics dissertation.

Nilsen, Don L. F. 1973. The Instrumental Case in English; Syntactic and Semantic Considerations. The Hague: Mouton.

Nissenbaum, Jon. 2005. Kissing Pedro Martinez: (existential) anankastic conditionals and rationale clauses. Proceedings from Semantics and Linguistic Theory 15, 134-51.

Portner, Paul. 1998. The progressive in modal semantics. Language 74(4), 760-87.

Randall, Janet H. 1992. The catapult hypothesis: an approach to unlearning. In J. Weissenborn, H. Goodluck \& T. Roeper (eds.), Theoretical Issues in Language Acquisition: Continuity and Change in Development, 93-138. Hillsdale, NJ: Lawrence Erlbaum.

Rappaport, Malka \& Beth Levin. 1988. What to do with theta roles. In Wendy Wilkins (ed.), Syntax and Semantics 21: Thematic Relations, 7-36. New York, NY: Academic Press.

Rissman, Lilia. 2010. Instrumental with, locatum with and the argument/adjunct distinction. LSA Meeting Extended Abstracts 2010.

Rissman, Lilia. to appear. Periphrastic use: a modal account of instrumentality. Proceedings of the 41st Annual Meeting of the North East Linguistics Society.

Sæbø, Kjell J. 2001. Necessary conditions in a natural language. In C. Féry \& W. Sternefeld (eds.), Audiatur Vox Sapientiae: a Festchrift for Arnim von Stechow, 472-449. Berlin: Akademie Verlag.

Saxe, Rebecca \& Susan Carey. 2006. The perception of causality in infancy. Acta Psychologica 123(1-2), 144-65.

Schlesinger, Izchak M. 1995. Cognitive Space and Linguistic Case. Cambridge: Cambridge University Press.

von Stechow, Arnim., S. Krasikowa \& Doris Penka. 2005. Anankastic conditionals. Ms., University of Tübingen: http://vivaldi.sfs.nphil.unituebingen. de/- arnim10/Aufsaetze/Nec.Cond6.pdf.

Talmy, Leonard. 1976. Semantic causative types. Syntax and semantics 6 . van Valin, Robert \& David Wilkins. 1996. The case for 'effector': case roles, agents, and agency revisited. In Masayoshi Shibatani \& Sandra A. Thompson 
Instrumental with and use

(eds.), Grammatical Constructions: Their Form and Meaning, 289-322. Oxford: Clarendon Press.

Werner, Tom. 2006. An analysis of existential anankastics: how to get there from here. Proceedings from Semantics and Linguistic Theory 16, 313-28.

Woodward, Amanda L. 2009. Infants' grasp of others' intentions. Current Directions in Psychological Science 18(1), 53-7.

Lilia Rissman

Krieger Hall 237

3400 N. Charles St.

Baltimore, MD 21218

rissman@cogsci.jhu.edu 